\title{
Cameron Lesions: Unusual Cause of Gastrointestinal Bleeding and Anemia
}

\author{
Kishore Maganty ${ }^{\mathrm{a}}$ Richard L. Smith ${ }^{\mathrm{b}}$ \\ a Internal Medicine Residency Program, Department of Medicine, and bepartment of Medicine and \\ Division of Gastroenterology, Southern Illinois University School of Medicine, Springfield, III., USA
}

\section{Key Words}

Cameron ulcers - Cameron erosions - Cameron lesions •

Hiatal hernia $\cdot$ Gastrointestinal bleeding $\cdot$ Anemia

\begin{abstract}
Cameron lesions are linear gastric ulcers or erosions on the mucosal folds at the diaphragmatic impression in patients with a large hiatal hernia. The clinical relevance of Cameron lesions is due to their potential complications such as gastrointestinal bleeding (acute, chronic and obscure) and anemia. The diagnosis is usually made during upper endoscopy. Medical therapy is the mainstay of treatment with few cases reserved for surgical correction.
\end{abstract}

Copyright $\odot 2008$ S. Karger AG, Basel

\section{Introduction}

Sliding hiatal hernias occur when the gastroesophageal junction and some portion of the stomach are displaced above the diaphragm. The cause of hiatal hernia is mostly unknown. The frequency of hiatal hernia increases with age [1]. It is a very common endoscopic finding. Hiatal hernias are usually asymptomatic but commonly associated with gastroesophageal reflux disease (GERD). Complications from hiatal hernia include iron deficiency anemia and acute and chronic bleeding, with and without ulcers or erosion. Other complications include mucosal prolapse, incarceration and volvulus and esophageal shortening [2].

Cameron erosions and ulcers represent the mild and severe forms of the same disease spectrum, respectively [3]. The exact prevalence of erosions and ulcers is not known. Because of the difficulty associated with differentiation between erosions and ulcers during endoscopy, the term Cameron lesions is used collectively to describe Cameron ulcers and erosions [4]. Cameron lesions are linear gastric ulcers or erosions on the mucosal folds at the diaphragmatic impression in patients with a large hiatal hernia [5]. They are found on the lesser curve of the stomach at the level of the diaphragmatic hiatus. The prevalence rates of hiatal hernia range from 0.8 to 2.9 in all patients undergoing upper gastrointestinal endoscopy [2]. Cameron lesions are seen in 5\% of patients with known hiatal hernia discovered on upper endoscopic studies $[1,5]$.

Cameron and Higgins [5] first described Cameron lesions in 1986. They studied 109 elderly patients prospectively who had endoscopically proven hiatal hernia. 55 patients were found to be anemic and 54 were not. In 23 patients with anemia, linear gastric erosions were seen on the crests of mucosal folds located at or near the level of the diaphragm, which were termed 'Cameron lesions'. Out of the 54 patients without anemia, 13 had endoscopic Cameron lesions [5].

\section{KARGER \\ Fax +41613061234 \\ E-Mail karger@karger.ch}

www.karger.com
(C) 2008 S. Karger AG, Basel

$0012-2823 / 08 / 0774-0214 \$ 24.50 / 0$

Accessible online at:

www.karger.com/dig
Kishore Maganty, MD

Department of Medicine, Southern Illinois University School of Medicine PO Box 19636

Springfield, IL 62794-9636 (USA)

Tel. +1 217545 0193, Fax +1 217545 8156, E-Mail kmaganty@siumed.edu 


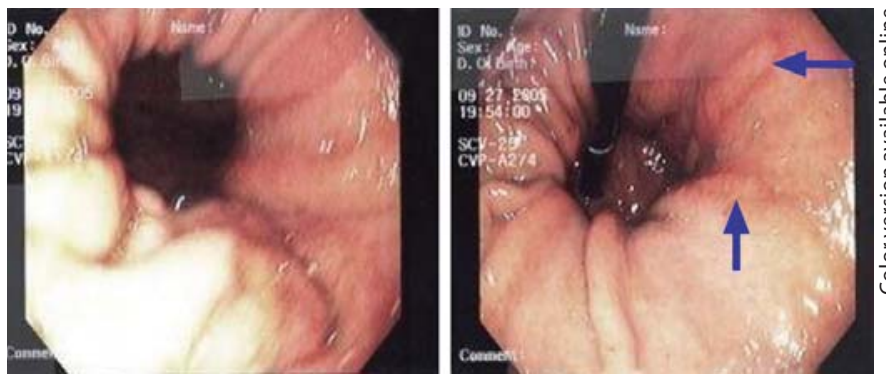

Fig. 1. Endoscopic appearance of Cameron lesions located in the neck of the hiatal hernia (arrows point at the lesion).

\section{Case Presentation}

A 65-year-old white female presented to the emergency room with a several-hour history of weakness, nausea and sweating. Her past medical history was significant for coronary artery disease, chronic obstructive pulmonary disease, hypertension, diabetes, mild normocytic anemia, GERD, dyslipidemia, depression, obesity, sleep apnea, and pulmonary fibrosis. Shortly after presentation, she had five episodes of hematemesis. The emergency room nurse noted some maroon-colored blood per rectum. She was hypotensive on admission to the ICU. Her abdomen was nontender. The patient was stabilized with fluids. She was started on proton pump inhibitor intravenously. Hemoglobin at presentation was $11.3 \mathrm{~g} / \mathrm{dl}$. The patient underwent esophagogastroduodenoscopy (EGD), which showed Cameron lesions in the distal hiatal hernia at the junction of the diaphragmatic junction (fig. 1) along with mild esophagitis. There were multiple lesions that had clean base without any stigmata of bleeding (non-bleeding visible vessels or adherent clots). No active bleeding was seen except for evidence of 'old' blood. No other sources of bleeding were disclosed on EGD to the duodenum and therefore no endoscopic therapy was instituted. The patient later had a drop in hemoglobin, which required transfusion. She stopped bleeding spontaneously without any intervention. The patient was discharged on proton pump inhibitors. Review of her old records showed that she had a similar presentation 2 months earlier. EGD at that time showed multiple superficial ulcerations in a large hiatal hernia along with erosive esophagitis. The patient was discharged on famotidine $40 \mathrm{mg}$, once a day, as her insurance company did not approve proton pump inhibitors. The patient's compliance with medications was questionable.

She continued to be anemic at follow-up. A panendoscopy was suggested by the gastroenterologist but the patient refused. She was instructed to take acid suppressants and iron supplements on a long-term basis because of chronic anemic. At the 1-year followup her hemoglobin was $12.5 \mathrm{~g} / \mathrm{dl}$.

This case illustrates the significance of hiatal hernia and Cameron lesions in the pathogenesis of gastrointestinal bleeding (both acute and chronic) and iron deficiency anemia.

\section{Etiology}

Various hypotheses have been proposed on the possible pathogenesis of Cameron lesions like mechanical trauma secondary to diaphragmatic contraction from respiratory excursions $[5,6]$ and acid injury [7]. Cameron and Higgins [5] used the former theory as an explanation for the formation of Cameron lesions. In an attempt to prove the later theory, Moskovitz et al. [7] studied 16 patients with anemia as the presenting problem and endoscopically proven Cameron lesions. Eight patients were treated with oral iron supplements only. Four of these 8 patients agreed to endoscopic follow-up and did not demonstrate healing. On the other hand, 11 patients ( 3 of the patients from the earlier group and 8 patients) treated with iron and histamine- 2 receptor blockers had healing of the lesions within 6 weeks.

Ischemia as a possible cause of Cameron lesions was also proposed. Moskovitz et al. [7] biopsied several Cameron lesions and found that histopathologically many of these lesions had focal ischemic gastropathy consisting of coagulation necrosis.

The role of Helicobacter pylori in the formation of Cameron lesions has been studied. In order to explore this possibility, Weston [4], in his patient population with Cameron lesions, took multiple gastric biopsies (including antrum) in 28 patients and tested for H. pylori. He found that only $32 \%$ (9 patients) were positive for Helicobacter. Other pathogenic factors postulated include gastric stasis, vascular stasis and edema.

\section{Pathophysiology and Clinical Features}

Hiatal hernia is a very common endoscopic finding, although asymptomatic in the majority of cases. The main clinical significance of the sliding hiatal hernia is its contribution to GERD. Hiatal hernias can cause iron deficiency anemia. In a prospective national populationbased study, risk of iron deficiency anemia was evaluated in patients with esophagitis and hiatal hernia. The hazard rate ratio for hiatal hernia was 2.9 (95\% confidence interval 1.5-5.5), which was significantly higher compared with a hazard rate ratio of 2.2 being found in patients with esophagitis [8]. Cameron [9] noted similar findings in a controlled study. The incidence of anemia in 259 patients with a diaphragmatic hernia large enough to be seen on a routine chest roentgenogram was compared with that in 259 age- and sex-matched controls. 18 patients with diaphragmatic hernia were anemic, compared 
to 1 control subject ( $\mathrm{p}<0.001$ ). In 13 patients with diaphragmatic hernia and in 1 control, the anemia proved to be caused by iron deficiency. Erosions in the form of Cameron lesions can cause iron deficiency from chronic blood loss. However, Panzuto et al. [10] and Pauwelyn and Verhamme [11] demonstrated that a large hiatal hernia could cause iron deficiency anemia, even without Cameron lesions.

The prevalence of Cameron lesions seems to be dependent on the size of the hiatal hernia. The risk is around $10-20 \%$ when the hernia size is $>5 \mathrm{~cm}$ [12]. In about two thirds of the cases, multiple lesions are noted rather than a solitary erosion or ulcer [1]. Common concomitant findings during endoscopic evaluation include erosive esophagitis and peptic disease.

Gastrointestinal bleeding, both acute and chronic, is reported in patients with hiatal hernia associated with Cameron lesions. The incidence of acute gastrointestinal bleeding varied in different series. In the original paper by Cameron and Higgins [5], acute gastrointestinal bleeding was rare in their patient population. However, Weston [4] in his population reported acute gastrointestinal bleeding of around 29\% (definitive 7.1\%, potential 21.4\%) secondary to Cameron lesions [4]. In a retrospective analysis by Hocking et al. [13], the rate of acute gastrointestinal bleeding was found to be as high as $58 \%$ [13]. Chronic blood loss, which historically is the known complication of the Cameron lesion, leads to anemia. Cameron lesions can be found as an incidental finding during EGD [1]. Weston [4] reported that about $50 \%$ of the Cameron lesions were incidental findings found on endoscopy done for some other reason.

\section{Diagnosis}

Clinical diagnosis of hiatal hernia and Cameron lesions is often difficult since they often present with GERD symptoms and anemia. Hiatal hernias are very common endoscopic findings. They are also found on chest X-rays as a large structure in the posterior mediastinum. An upper gastrointestinal series is a very useful non-invasive modality to diagnose and study hiatal hernia.

Unlike hiatal hernia, which hosts the Cameron lesions, Cameron lesions are rarely found on radiographic films. Endoscopy is considered the gold standard but it is not uncommon to miss these lesions. The endoscopic assessment involves careful antegrade and retrograde visualization of the region as well as perpendicular views of the hernial neck and adjacent mucosa. Magnification chromoendoscopy may be useful in some cases to demonstrate mucosal defects in the absence of well-defined lesions [12]. Endoscopic findings such as edema, erythematous changes, and ecchymotic bleeding may accompany Cameron lesions in the gastric mucosal folds [5, 14]. In patients with obscure gastrointestinal bleeding, Cameron lesions are an important entity to keep in mind. Occasionally, they are missed on first EGD $[15,16]$ and are discovered during a 'second-look' endoscopy or push enteroscopy [17]. The role of capsule endoscopy in diagnosing Cameron lesions has not been defined.

\section{Treatment}

Treatment is primarily medical and surgery is reserved for refractory cases and a few complicated cases. Acid suppressants along with prokinetic agents are the drugs of choice $[1,4,5,7]$. Iron supplementation is given in conjugation with acid suppressants in patients with concomitant anemia [7]. Most of the patients with Cameron lesions are found to have some kind of acid-related problems (reflux disease, esophagitis, peptic ulcer, etc.), so it is not unusual for patients to be on acid inhibitors before Cameron lesions are discovered. In such circumstances, intensification of the treatment is recommended for healing of the lesions [4]. In a small case series, it was found that diagnosis of linear gastric lesions in the giant hiatal hernia changed the outcomes of the disease and led to appropriate utilization of the healthcare resources compared to not diagnosing the condition resulting in repeat hospitalization, multiple endoscopic procedures and transfusions [3].

A case report with life-threatening gastrointestinal bleeding secondary to Cameron lesion treated successfully with band ligation of a visible vessel has been reported. However, it should be noted that endoscopic hemostasis is difficult in such scenarios due to anatomic and technical reasons [18]. Surgical treatment (fundoplication - laparoscopic or open) is recommended in patients with medically refractory disease [11, 19], uncontrolled bleeding from the lesions and in patients in whom the hernia is complicated with volvulus, incarceration and perforation [4]. Endoscopic plication is a novel and emerging treatment option for patients with GERD and hiatal hernia [20,21]. Given the close association of hiatal hernia and Cameron lesions, endoscopic plication might be a reasonable treatment option for Cameron lesions as well. 


\section{Prognosis}

The success rate of medical therapy is very high. Moskovitz et al. [7] demonstrated an endoscopic healing rate of $64 \%$ when treated with histamine- 2 receptor blockers and iron at 6 weeks. Similarly, Weston [4] in his study fol- lowed patients for about 34 months and noted 20\% complications from the Cameron lesions either in the form of rebleeding (3 patients), persistent anemia (4 patients) and death in 1 patient. Long-term follow-up failed to show evidence of recurrence of ulcer or hemorrhage after surgical treatment [22].

\section{References}

1 Sleisenger \& Fordtran's Gastrointestinal and Liver Disease, ed 7. Philadelphia, Saunders, 2002.

-2 Johnson DA, Ruffin WK: Hiatal hernia. Gastrointest Endosc Clin N Am 1996;6:641667.

3 Dulai D, Jensen ME, Lam F, Jutabha R, Jensen DM: Occult gastrointestinal hemorrhage from linear gastric ulcers in giant, sliding hiatal hernias: an enteroscopic case series (abstract). Gastrointest Endosc 1999;49: AB166.

-4 Weston AP: Hiatal hernia with Cameron ulcers and erosions. Gastrointest Endosc Clin N Am 1996;6:671-679.

$\checkmark 5$ Cameron AJ, Higgins JA: Linear gastric erosion. A lesion associated with large diaphragmatic hernia and chronic blood loss anemia. Gastroenterology 1986;91:338-342.

6 Richter IA, Rabin MS: The 'riding' ulcer: a report of three cases. S Afr Med J 1979;56: 612-614.

$\checkmark 7$ Moskovitz M, Fadden R, Min T, Jansma D, Gavaler J: Large hiatal hernias, anemia, and linear gastric erosion: studies of etiology and medical therapy. Am J Gastroenterol 1992; 87:622-626.

$\checkmark 8$ Ruhl CE, Everhart JE: Relationship of irondeficiency anemia with esophagitis and hiatal hernia: hospital findings from a prospective, population-based study. Am J Gastroenterol 2001;96:322-326.
Cameron AJ: Incidence of iron deficiency anemia in patients with large diaphragmatic hernia. A controlled study. Mayo Clin Proc 1976;51:767-769.

10 Panzuto F, Di Giulio E, Capurso G, Baccini F, D’Ambra G, Delle Fave G, Annibale B: Large hiatal hernia in patients with iron deficiency anaemia: a prospective study on prevalence and treatment. Aliment Pharmacol Ther 2004;19:663-670.

11 Pauwelyn KA, Verhamme M: Large hiatal hernia and iron deficiency anaemia: clinicoendoscopical finding. Acta Clin Belg 2005; 60:166-172.

12 Nguyen N, Tam W, Kimber R, RobertsThomson IC: Gastrointestinal: Cameron's erosions. J Gastroenterol Hepatol 2002;17: 343.

13 Hocking RV, Alp MH, Grant AK: Gastric ulceration within hiatus hernia. Med J Aust 1976;2:207-208.

14 Miller G: Linear gastric erosion associated with diaphragmatic hernia. Gastroenterology $1987 ; 92: 271$.

15 Bornstein JD, Brazer SR: Cameron erosions. Gastrointest Endosc 1999;49:514.

16 Appleteard MN, Swain CP: Endoscopic difficulties in the diagnosis of upper gastrointestinal bleeding. World J Gastroenterol 2001;7:308-312.
Zaman A, Katon RM: Push enteroscopy for obscure gastrointestinal bleeding yields a high incidence of proximal lesions within reach of a standard endoscope. Gastrointest Endosc 1998;47:372-376.

18 Lin CC, Chen TH, Ho WC, Chen TY: Endoscopic treatment of a Cameron lesion presenting as life-threatening gastrointestinal hemorrhage. J Clin Gastroenterol 2001;33: 423-424.

19 Moschos J, Pilpilidis I, Kadis S, Antonopoulos Z, Paikos D, Tzilves D, Katsos I, Tarpagos A: Cameron lesion and its laparoscopic management. Indian J Gastroenterol 2005;24: 163.

20 Rothstein R, Filipi C, Caca K, Pruitt R, Mergener K, Torquati A, Haber G, Chen Y, Chang K, Wong D, Deviere J, Pleskow D, Lightdale C, Ades A, Kozarek R, Richards W, Lembo A: Endoscopic full-thickness plication for the treatment of gastroesophageal reflux disease: a randomized, sham-controlled trial. Gastroenterology 2006;131:704-712.

21 Chen YK, Raijman I, Ben-Menachem T, Starpoli AA, Liu J, Pazwash H, Weiland S, Shahrier M, Fortajada E, Saltzman JR, CarrLocke DL: Long-term outcomes of endoluminal gastroplication: a US multicenter trial. Gastrointest Endosc 2005;61:659-667.

22 Cougard P, Sala JJ, Favre JP, Viard H: Ulcers of the neck of hiatal hernia. 15 cases. J Chir 1985;122:399-402. 